Title:

\title{
Estimating the relative contribution of comorbidities in predicting health-related quality of life of people with multiple sclerosis
}

\section{Authors:}

Lara Marie Pangan Lo ${ }^{1}$, Bruce V. Taylor ${ }^{1}$, Tania Winzenberg ${ }^{1}$, Andrew J. Palmer ${ }^{1,2}$, Leigh Blizzard $^{1}$, Hasnat Ahmad ${ }^{1}$, Mohammad Akhtar Hussain' ${ }^{1}$, Ingrid van der Mei ${ }^{1, *}$

${ }^{1}$ Menzies Institute for Medical Research, University of Tasmania, Hobart, TAS 7000, Australia

${ }^{2}$ Centre for Health Policy, School of Population and Global Health, The University of Melbourne, Melbourne, Victoria 3053

\section{*Corresponding Author:}

A/Prof Ingrid van der Mei

Menzies Institute for Medical Research, University of Tasmania,

17 Liverpool Street, Hobart, TAS 7000, Australia.

Phone: (61) 362267710 and Fax: (61) 362267704

Email: Ingrid.vanderMei@utas.edu.au

Keywords: comorbidity, quality of life, multiple sclerosis, general dominance analysis, relative contribution, AQoL-8D 
Impact of comorbidities on HRQoL in MS

\section{Abstract}

Background: Little is known about the relative contribution of comorbidities in predicting the health-related quality of life (HRQoL) of people with Multiple Sclerosis (PwMS).

Objective: To determine the associations between the number of and individual comorbidities and HRQoL and estimate the relative contribution of different comorbidities on HRQoL.

Methods: Cross-sectional analysis of data on self-reported presence of 30 comorbidities and HRQoL from the Australian MS Longitudinal Study (AMSLS) participants(n=902). HRQoL was measured using the Assessment of Quality of Life-8 Dimensions (AQoL-8D). Linear regression and general dominance analysis were used.

Results: Higher number of comorbidities was associated with lower HRQoL ( $p$-trend $p<0.01$ ). Comorbidities accounted for $18.1 \%$ of the variance in HRQoL. Mental health and musculoskeletal disorders were the strongest contributors to lower HRQoL. Of individual comorbidities, systemic lupus erythematosus (SLE) $(\beta=-0.16(-0.27,-0.05))$ and depression $(\beta=-$ $0.15(-0.18,-0.13))$ were most strongly associated with overall HRQoL, depression $(\beta=-0.14(-$ $0.16,-0.11))$ and anxiety $(\beta=-0.10(-0.13,-0.07))$ with psychosocial HRQoL, and SLE $(\beta=-0.18(-$ $0.29,-0.07))$, rheumatoid arthritis $(\beta=-0.11(-0.19,-0.02))$ and hyperthyroidism $(\beta=-0.11(-0.19,-$ 0.03)) with physical HRQoL.

Conclusions: Comorbidities potentially make important contributions to HRQoL in PwMS. Our findings highlight groups of and individual comorbidities that could provide the largest benefits for the HRQoL of PwMS if they were targeted for prevention, early detection, and optimal treatment. 


\section{Introduction}

One facet of Multiple Sclerosis (MS) management that has garnered significant research interest is enhancing the overall health-related quality of life (HRQoL) of people with MS (PwMS). HRQoL is a subjective concept capturing overall well-being and is defined by the World Health Organization as the "individual's perception of their position in life in the context of the culture and value systems in which they live and in relation to their goals, expectations, standards and concerns". ${ }^{1}$ Specifically, the MS International Federation describes the HRQoL of PwMS as multifaceted, highly interchangeable but very personal and influenced by many factors such as the environment, and various social circumstances. ${ }^{2}$ In MS, previous studies have already identified that age, sex, socio-economic status, disability progression, symptoms and other disease features can lower the HRQoL of PwMS. ${ }^{3-6}$

PwMS are more likely to acquire comorbidities and have a lower HRQoL compared to the general population and to those with other chronic conditions. ${ }^{7,8}$ Identifying the groups of or individual comorbidities that are associated with the largest reductions in HRQoL of PwMS could influence the recommendations around comorbidity screening and management. However, knowledge on the relative contribution of comorbidities as predictors of HRQoL in MS is very limited. Most studies have focussed on the total burden of comorbidities or only examined the associations between a small number of individual comorbidities and physical or mental HRQoL. ${ }^{4,5,7,9-11}$ No studies have investigated the relative contribution of comorbidities to the HRQoL of PwMS.

Using the comorbidity data of the Australian MS Longitudinal Study (AMSLS) participants, we aimed to (a) examine associations between the number of comorbidities and HRQoL; (b) estimate the relative contribution of groups of comorbidities in predicting HRQoL and; (c) determine the magnitude of the effects of individual comorbidities on HRQoL. 
Impact of comorbidities on HRQoL in MS

\section{Methodology}

\section{Study population}

The AMSLS is a large sample of around 3,000 adult Australian volunteers with MS. ${ }^{12}$ An estimated $96 \%$ of the participants were diagnosed by a neurologist with definite MS using the McDonald Criteria. ${ }^{13,14}$ It is an ongoing survey-based research project supported by MS societies in all Australian states and territories. Ethical approval was initially given by the Australian Capital Territory Health Human Research Ethics Committee (HREC) and by the Tasmanian Health and Medical HREC when the study centre was relocated to Tasmania in 2014. ${ }^{12}$ All participants provided informed consent.

In 2016, active AMSLS participants were invited to complete 3 surveys. To assess comorbidities, we used the Lifestyle and Environment Survey ((August-October 2016); 3,112 invitations sent; $1,518(49 \% ; 1,067$ online and 451 paper) responded). To obtain clinical information, we used the Medication and Disease Course Survey ((November 2016-March 2017); 3,098 invitations sent; 1,699 (55\%; 1,282 online and 417 paper) responded). To assess HRQoL, we used the Economic Impact Baseline Survey ((March-May 2016); 3,163 invitations sent; 1,577 (50\%; 1,112 online and 465 paper) responded). We included those who completed all three surveys $(\mathrm{N}=902)$.

\section{Measurements}

\section{Comorbidities}

The participants were asked about the presence of 30 comorbidities that were frequently reported in prior comorbidity studies in MS. ${ }^{15-17}$ For each comorbidity, we asked "Do you have or have you had this condition?" (Yes/No). If yes, the participant was coded as having that comorbidity. We subsequently asked "Was it diagnosed by a doctor?” (Yes/No/Don't know). If yes, the participant was coded as having that doctor-diagnosed comorbidity. The "Don't 
know" group was combined with the "No" group. The total comorbidities (i.e. any comorbidity the patient reported having) and doctor-diagnosed comorbidities (i.e. any comorbidity the patient reported as diagnosed by a doctor) were counted. The comorbidities were grouped according to the 263 blocks (disease categories) in the International Classification of Diseases$10^{\text {th }}$ revision (ICD-10) structure. Because of power considerations, only those comorbidities reported by at least 10 participants were assessed for their influence on HRQoL which excluded Parkinson's disease, bipolar disorder and schizophrenia. The complete list of the 27 included individual comorbidities and the 13 comorbidity groups to which they belong are shown in Table 1.

\section{HRQoL}

We assessed HRQoL using the Assessment of Quality of Life-8 Dimensions (AQoL-8D) questionnaire, a comprehensive HRQoL instrument that describes billions of health states $(2.4$ $\mathrm{x} 10^{23}$ ) and has 35 items with 2 super-dimensions and 8 domains (psychosocial superdimension (domains of happiness, coping, relationships, self-worth, and mental health) and physical super-dimension (domains of independent living, senses and pain)). ${ }^{18}$ The AQoL-8D has been validated for use for people with complex and chronic conditions like MS and only takes around 5 minutes to complete. ${ }^{19,}{ }^{20}$ Scores range from 0 (death/worst health state) to 1 (perfect health).

\section{$\underline{\text { Other measures }}$}

MS duration was calculated by subtracting years since MS diagnosis from the survey date. Body mass index (BMI) was calculated by dividing self-reported weight (in kilograms) by height $^{2}$ (in centimetres). Data on sex, disease modifying therapy status, MS onset-type (i.e. 
Impact of comorbidities on HRQoL in MS

relapse-onset and progressive-onset) and education attainment were also obtained from the 2016 Medication and Disease Course Survey.

\section{Statistical analysis}

We used descriptive statistics to summarize participant characteristics. To ascertain the generalisability across the sample, we compared the characteristics of the included vs notincluded participants by performing student t-test and $\chi^{2}$ test. Associations between the number of comorbidities and AQoL-8D was evaluated using linear regression. A dose-response was assessed using a test-for-trend. We then performed a multivariable regression analysis by including all the comorbidity groups as predictor variables in the model and determined the association of each comorbidity groups on the overall AQoL-8D. Since a certain degree of correlation exists between the predictors in the model, we carried out general dominance analysis (domin package in Stata) to determine the relative contribution (\%) each of the predictors made to the overall AQoL-8D. ${ }^{21,22}$ Dominance analysis provides an intuitive measure of predictor importance in two ways: 1) it uses the change in model fit (i.e., $\mathrm{R}^{2}$ ) to determine the contribution of each predictor, and 2) it compares predictor contributions across all possible subset models from a given set of predictors. ${ }^{23,24}$ Results were presented as general dominance weights, standardized to be out of $100 \%$, to provide a ranking and weighting for each predictor in the model. ${ }^{23} \mathrm{We}$ further examined the association of individual comorbidities and overall AQoL-8D by linear regression. We used those with no comorbidity as the reference group. Potential confounders were identified by using causal diagrams and by examining whether the coefficient of each outcome (i.e. AQoL-8D) variable was altered by more than $10 \%$ when a covariate (i.e. age, sex, MS duration, MS onset-type (relapse-onset vs. progressive-onset) and education attainment) was added to the model. ${ }^{25,}{ }^{26} \mathrm{We}$ repeated all the analyses above for AQoL-8D's physical and psychosocial super-dimensions. We performed 
sensitivity analyses by limiting to doctor-diagnosed comorbidities. For musculoskeletal disorders, we were concerned that the impact was driven by the systemic component of rheumatoid arthritis and SLE. We therefore repeated the analysis excluding these comorbidities. We performed regression diagnostics and examined residual errors for all models, but no transformations were needed. All analyses were performed using STATA/IC for Windows (version 15.0; StataCorp LP, College Station, Texas, USA).

\section{Results}

\section{Prevalence of comorbidities}

Of the total cohort, $91.1 \%(\mathrm{n}=817)$ of participants had $\geq$ one comorbidity. The most prevalent mental health comorbidities were depression (41.2\%) and anxiety (38.1\%) (Table 1). Common physical comorbidities included allergies (37.4\%), hypertension (29.9\%), migraine (26.9\%), high cholesterol $(24.1 \%)$, osteoarthritis $(22.2 \%)$, eye diseases $(15.0 \%)$, cancer $(14.6 \%)$ and osteoporosis (13.8\%) (Table 1).

\section{Participant characteristics}

Participants were predominantly female (78.6\%) and had a mean age of 55.8 years (Table 2). The average MS duration since diagnosis was 15.4 years, most had relapse-onset MS (87.4\%), $62.6 \%$ were currently receiving disease modifying therapy and $42.2 \%$ had normal BMI (as defined by $\mathrm{BMI}=18.5$ to 25.0$)$.

The participants included in this analysis had a similar sex distribution $(78.6 \%$ females vs. $78.7 \%, p=0.95)$ to participants who were not included. Included participants were slightly older $(+1.80$ years, $p<0.01)$, had longer MS duration $(+1.20$ years $p<0.01)$ and higher education attainment (39\% with university degree or higher vs $33 \%, p=0.01)$. 
Impact of comorbidities on HRQoL in MS

\section{Association between the number of comorbidities and AQoL-8D}

A higher number of comorbidities was associated with lower overall AQoL-8D and AQoL8D's physical and psychosocial super-dimensions with a clear dose-response relationship (Table 3), which persisted after adjusting for age, sex and education attainment. We found no significant interactions between number of comorbidities and MS onset-type or sex for both total and doctor-diagnosed comorbidities (data not shown).

\section{Relative contribution of comorbidity groups to overall AQoL-8D}

All the comorbidity groups $(n=13)$ accounted for $18.1 \%$ of the variance in the overall AQoL$8 \mathrm{D}$ variable (Figure 1). Using general dominance analysis, we identified that $68.3 \%$ of this variance was contributed by mental health disorders followed by musculoskeletal disorders $(12.6 \%)$. When rheumatoid arthritis and SLE were excluded from the musculoskeletal disorder group, the contribution of this group reduced from $12.6 \%$ to $10.8 \%$. When we limited our analysis to doctor-diagnosed comorbidities, similar findings were observed (61.5\% of the total $14.7 \%$ variance in overall AQoL-8D was contributed by mental health disorders; $12.7 \%$ by musculoskeletal disorders) (Supplementary Figure 1).

\section{Relative contribution of comorbidity groups to AQoL-8D's physical and psychosocial super-}

\section{dimensions}

The 13 comorbidity groups together accounted for $17.5 \%$ of the variance of the AQoL-8D's psychosocial super-dimension and $12.7 \%$ of the variance in AQoL-8D's physical superdimension (Figure 1). Mental health disorders contributed $80.9 \%$ and $19.7 \%$ of the AQoL-8D's psychosocial and physical super-dimensions total variance respectively, making this group the strongest contributor of psychosocial HRQoL and the second most important contributor of physical HRQoL. Musculoskeletal disorders contributed 5.5\% and 38.9\% of the total AQoL8D's psychosocial and physical super-dimensions variance, respectively. This comorbidity 
Impact of comorbidities on HRQoL in MS

group is the second most important contributor to psychosocial HRQoL and the most important contributor to physical HRQoL. Similar patterns were seen with doctor-diagnosed comorbidities (Supplemental Figure 1).

\section{Association between individual comorbidities and overall AQoL-8D}

The mean overall AQoL-8D for PwMS with no reported comorbidities was 0.74 (95\% CI: 0.69, 0.78) after adjusting for age, sex and education attainment (Table 4). The comorbidities with an effect size greater than the recognised minimum important difference for the AQoL-8D (defined as $\beta \geq 0.08)^{19}$ were systemic lupus erythematosus (SLE) $(\beta=-0.16)$, depression $(\beta=-$ $0.15)$, hyperthyroidism $(\beta=-0.12)$, anxiety $(\beta=-0.11)$, inflammatory bowel disease (IBD) $(\beta=-$ $0.10)$, rheumatoid arthritis $(\beta=-0.09)$, osteoporosis and type 2 diabetes $(\beta=-0.08)$. Other autoimmune diseases, heart diseases, osteoarthritis, migraine and allergies were also significantly associated with a lower AQoL-8D but the effect sizes were lower ( $\beta$ from -0.03 to -0.07). The effect sizes for doctor-diagnosed comorbidities were similar (Supplementary Table 1).

Association between individual comorbidities and AQoL-8D's physical and psychosocial super-dimensions

The mean AQoL-8D's psychosocial super-dimension for PwMS with no reported comorbidities was 0.45 (95\% CI: 0.41,0.49) and their mean AQoL-8D's physical superdimension was 0.68 (95\% CI: 0.64,0.72) after adjusting for age, sex and education attainment (Table 5). The comorbidities that were significantly associated with AQoL-8D's psychosocial super-dimension with $\beta \geq 0.08$ were depression $(\beta=-0.14)$, anxiety $(\beta=-0.10)$, hyperthyroidism $(\beta=-0.09)$ and IBD $(\beta=-0.08)$. SLE had an effect size of $\beta=-0.09$ but the association was not statistically significant. The effect sizes for doctor-diagnosed comorbidities were similar, although the effect size of IBD was lower and not significant $((\beta=-0.07)$ (Supplementary Table 
2). The comorbidities that were significantly associated with AQoL-8D's physical superdimension with $\beta \geq 0.08$ were SLE ( $\beta=-0.18)$, rheumatoid arthritis, hyperthyroidism $(\beta=-0.11)$, depression, IBD and other autoimmune diseases $(\beta=-0.10)$. Epilepsy and type 1 diabetes had effect sizes of $\beta=-0.11$ and $\beta=-0.08$, respectively and but the associations were not statistically significant. Again, the effect sizes for the doctor-diagnosed comorbidities were similar (Supplementary Table 2).

\section{Discussion}

This study, to the best of our knowledge, is the first to use a more superior and sensitive HRQoL instrument (i.e. AQoL-8D) to assess the relative contribution of different comorbidities grouped into ICD-10 categories and to estimate the magnitude of effects of a wide range of individual comorbidities on HRQoL. In this large population-based study of PwMS, the number of comorbidities was strongly associated with lower AQoL-8D in a dose-dependent fashion and comorbidities explained $18.1 \%$ of the variance of AQoL-8D score. Of all comorbidity groups, mental health disorders contributed most to overall AQoL-8D $(68.1 \%$ of the overall comorbidity effect), with an even higher contribution seen for AQoL-8D's psychosocial super-dimension (80.9\%). Musculoskeletal disorders (38.9\%) contributed most to AQoL-8D's physical super-dimension. Of the individual comorbidities, the magnitude of effects on overall AQoL-8D were largest for SLE, depression, hyperthyroidism, anxiety, IBD, rheumatoid arthritis, osteoporosis and type 2 diabetes. These findings suggest that prevention and management of these comorbidities has the greatest potential to have an important impact on the HRQoL of PwMS. 
PwMS who did not report any comorbidity had a mean overall AQoL-8D of 0.73 which is considerably lower than the previously reported overall AQoL-8D of the general Australian population $(\sim 0.80) .{ }^{27}$ Those with 2 or 3 comorbidities had a mean overall AQoL-8D of 0.65 while those with 4 or more comorbidities had a mean of 0.55 , which is 0.08 and 0.18 units lower than those without comorbidities, and likely to be clinically important. Our observed association aligns with other studies. ${ }^{4,7,9}$ Given the high proportions of PwMS reporting comorbidities $(\sim 90 \% \geq 1$ comorbidity, $\sim 36 \%$ with $2-3$ comorbidities, and $\sim 41 \%$ with $\geq 4$ comorbidities), there is therefore potential for a major gain in HRQoL through the prevention and optimal management of comorbidities.

The comorbidity groups combined explained $18.1 \%$ of the variance of overall AQoL-8D, $17.5 \%$ of AQoL-8D's psychosocial super-dimension and 12.7\% of AQoL-8D's physical superdimension. Of that variance explained, our results highlighted that mental health disorders (including depression and anxiety) were by far the largest contributor to the overall $(68.3 \%)$ and psychosocial super-dimension (80.9\%) of AQoL-8D. Musculoskeletal disorders (i.e. osteoporosis, osteoarthritis, rheumatoid arthritis and SLE) were the largest contributors to the AQoL-8D's physical super-dimension (38.9\%) and were the second largest contributor to overall AQoL-8D (12.6\%). Other comorbidity groups only had a relatively minor contribution in predicting the HRQoL of PwMS. Our findings were similar irrespective of whether we used the total or doctor-diagnosed comorbidities. Interestingly, a companion paper in this issue shows that mental health and musculoskeletal disorders were also the strongest contributors to the severity of the most common symptoms in MS. ${ }^{28}$ Collectively, our results emphasize the importance of early and routine screening of mental health and musculoskeletal disorders in achieving a better HRQoL in PwMS.

The large contribution of mental health disorders to HRQoL in our study highlights the importance of these disorders in MS. For the individual mental health disorders, people with 
depression had an overall AQoL-8D reduction of 0.15 units, and those with anxiety a reduction of 0.11 units, with similar magnitude of effects were seen for AQoL-8D's psychosocial superdimension and smaller but still potentially important effects on AQoL-8D's physical superdimension. The results in our study are similar to a large effect size for depression and moderate effect size for anxiety on mental HRQoL of PwMS found by Berrigan et.al. ${ }^{9}$ These large effect sizes together with depression and anxiety having the highest prevalence of all comorbidities (33.6\% reported as doctor-diagnosed depression, $20.2 \%$ reported as doctor-diagnosed anxiety) suggests that the population as well as the individual level impact of these comorbidities is substantial. We acknowledge that depression and anxiety could be the result of having MS or they could occur independently. In either case, our findings strongly support the notion that prompt and continuous screening during the disease course for these comorbidities should be conducted in PwMS, ${ }^{29-31}$ and that appropriate support and treatment should be pursued in order to minimise their impact.

Musculoskeletal disorders contributed the most to the variance in AQoL-8D's physical superdimension, whether we used total or doctor-diagnosed comorbidities. SLE was most strongly associated with a lower AQoL-8D's physical super-dimension (-0.16) followed by rheumatoid arthritis (-0.09) although the prevalence of these comorbidities was relatively low. The impact of this comorbidity group remained the same when the analysis was limited to those with osteoporosis and osteoarthritis, suggesting the impact is largely driven by the physical disabilities rather than systemic effects associated with SLE and rheumatoid arthritis. Overall, musculoskeletal disorders are considered a major cause of physical disability and a significant contributor to pain. ${ }^{32}$ The pain and the physical limitations brought by these comorbidities also affect the AQoL-8D's psychosocial super-dimension. Similar to our results, Woolf and Pfleger found that rheumatoid arthritis was more disabling than osteoarthritis or osteoporosis and was associated with a shorter life expectancy and even lower HRQoL particularly for those with 
severe forms of the disease. ${ }^{32}$ Osteoporosis contributed to a much lower HRQoL by substantially increasing long-term physical disability while the pain and disability experienced by those with osteoarthritis may lead to deterioration of health and wellbeing leading to a lower HRQoL of PwMS. ${ }^{33}$ Overall, recognising the large impact, instituting a timely intervention and developing preventative strategies to mitigate the occurrence or slow the progression of these comorbidities may result in a substantial improvement of HRQoL of PwMS.

A major strength of this study is the inclusion of broad range of comorbidities, which also allowed us to group comorbidities and identify the relative contribution of these comorbidity groups on HRQoL. The study limitations should also be recognized. The cross-sectional nature of our study precludes us from establishing causality between MS, comorbidities and HRQoL. Although the AMSLS is a highly representative sample of the MS population, ${ }^{12}$ some selection bias may have occurred as not all participants answered all 3 surveys. However, when we compared those who were included with those who were not included, differences in age, MS duration and education attainment were small. Further, our study sample is similar in sex and MS onset-types compared with other MS cohort studies, ${ }^{34}$ making our results likely generalisable to the whole MS population. Despite our large sample size, we had to exclude rare comorbidities due to power considerations. The comorbidities were self-reported, which might have caused some measurement error. To minimise this, we also asked whether the comorbidities were doctor-diagnosed. We found similar results for total and doctor-diagnosed comorbidities.

In conclusion, comorbidities have a major impact of HRQoL in people with MS. By examining comorbidity groups and individual comorbidities our results specifically highlighted that mental health and musculoskeletal disorders have a substantial impact on HRQoL and should be targeted for early detection, prevention and optimal treatment in PwMS. 


\section{Acknowledgement}

The authors would like to express their deepest gratitude for all the participants of the Australian Multiple Sclerosis Longitudinal Study for their continuous support and enthusiasm to respond to all surveys.

\section{Disclosure of conflicts of interest}

The authors declare that there are no conflicts of interest.

\section{Funding/Support}

This study was supported by Multiple Sclerosis Research Australia.

\section{References}

1. World Health Organization. WHOQOL: Measuring quality of life, https://www.who.int/healthinfo/survey/whoqol-qualityoflife/en/ (1997, accessed 12 June 2018).

2. MS International Federation. What influences quality of life with MS and how can we improve it?, https://www.msif.org/living-with-ms/what-influences-quality-of-life/ (accessed 27 June 2018).

3. Nortvedt MW, Riise T, Myhr KM, et al. Quality of life in multiple sclerosis: Measuring the disease effects more broadly. Neurology 1999; 53: 1098-1103.

4. Warren SA, Turpin KVL, Pohar SL, et al. Comorbidity and Health-Related Quality of Life in People with Multiple Sclerosis. Int J MS Care 2009; 11: 6-16.

5. Janzen W, Turpin KVL, Warren SA, et al. Change in the Health-Related Quality of Life of Multiple Sclerosis Patients over 5 Years. Int J MS Care 2013; 15: 46-53.

6. Ahmad H, Taylor BV, Mei Ivd, et al. The impact of multiple sclerosis severity on health state utility values: evidence from Australia. Mult Scler J 2017; 23: 1157-1166.

7. Marrie RA, Horwitz R, Cutter G, et al. Cumulative impact of comorbidity on quality of life in MS. Acta Neurol Scand 2012; 125: 180-186. DOI: https://doi.org/10.1111/j.16000404.2011.01526.x.

8. Hermann BP, Vickrey B, Hays RD, et al. A comparison of health-related quality of life in patients with epilepsy, diabetes and multiple sclerosis. Epilepsy Res 1996; 25: 113-118. 
9. Berrigan LI, Fisk JD, Patten SB, et al. Health-related quality of life in multiple sclerosis: Direct and indirect effects of comorbidity. Neurology 2016; 86: 1417-1424. DOI: https://doi.org/10.1212/WNL.0000000000002564.

10. Turpin KVL, Carroll LJ, Cassidy JD, et al. Deterioration in the health-related quality of life of persons with multiple sclerosis: the possible warning signs. Mult Scler J 2007; 13: 1038-1045.

11. Weiland TJ, De Livera AM, Brown CR, et al. Health Outcomes and Lifestyle in a Sample of People With Multiple Sclerosis (HOLISM): Longitudinal and Validation Cohorts. Front Neurol 2018; 9. DOI: https://doi.org/10.3389/fneur.2018.01074.

12. Taylor BV, Palmer A, Simpson Jr S, et al. Assessing possible selection bias in a national voluntary MS longitudinal study in Australia. Mult Scler J 2013; 19: 1627-1631. DOI: https://doi.org/10.1177/1352458513481511.

13. Polman $\mathrm{CH}$, Reingold SC, Banwell B, et al. Diagnostic criteria for multiple sclerosis: 2010 revisions to the McDonald criteria. Ann Neurol 2011; 69: 292-302. DOI: https://doi.org/10.1002/ana.22366.

14. McDonald WI, Compston A, Edan G, et al. Recommended Diagnostic Criteria for Multiple Sclerosis: Guidelines from the International Panel on the Diagnosis of Multiple Sclerosis. Ann Neurol 2001; 50: 121-127. DOI: https://doi.org/10.1002/ana.1032.

15. Marrie RA, Cohen J, Stuve O, et al. A systematic review of the incidence and prevalence of comorbidity in multiple sclerosis: Overview. Mult Scler J 2015; 21: 263-281. DOI: https://doi.org/10.1177/1352458514564491.

16. Kang $\mathrm{JH}$, Chen $\mathrm{YH}$ and Lin HC. Comorbidities amongst patients with multiple sclerosis: a population-based controlled study. Eur J Neurol 2010; 17: 1215-1219. DOI: https://doi.org/10.1111/j.1468-1331.2010.02971.x.

17. Marrie R, Horwitz R, Cutter G, et al. Comorbidity, socioeconomic status and multiple sclerosis. Mult Scler 2008; 14: 1091-1098. DOI: https://doi.org/10.1177/1352458508092263.

18. Richardson J, Sinha K, Iezzi A, et al. Modelling utility weights for the Assessment of Quality of Life (AQoL)-8D. Qual Life Res 2014; 23: 2395-2404.

19. Campbell JA, Hensher M, Neil A, et al. An Exploratory Study: A Head-to-Head Comparison of the EQ-5D-5L and AQoL-8D for Long-Term Publicly Waitlisted Bariatric Surgery Patients Before and 3 Months After Bariatric Surgery. Pharmacoecon Open 2018; 2: 443-458.

20. Richardson J, Iezzi A, Khan MA, et al. Validity and Reliability of the Assessment of Quality of Life (AQoL)-8D Multi-Attribute Utility Instrument. Patient 2014; 7: 85-96.

21. Luchman J. DOMIN: Stata module to conduct dominance analysis, https://ideas.repec.org/c/boc/bocode/s457629.html (2013, accessed April 16 2018).

22. Nathans LL, Oswald FL and Nimon K. Interpreting Multiple Linear Regression: A Guidebook of Variable Importance. Practical Assessment, Research \& Evaluation 2012; 17: $1-19$. 
23. Azen R and Budescu D. The Dominance Analysis Approach for Comparing Predictors in Multiple Regression. Psychol Methods 2003; 8: 129-148.

24. Azen R and Traxel N. Using Dominance Analysis to Determine Predictor Importance in Logistic Regression. J Educ Behav Stat 2009; 34: 319-347.

25. Greenland S. Modeling and variable selection in epidemiologic analysis. Am J Public Health 1989; 79: 340-349.

26. Kamangar F. Confounding Variables in Epidemiologic Studies: Basics and Beyond. Arch Iran Med 2012; 15: 508-516.

27. Maxwell A, Özmen M, Iezzi A, et al. Deriving population norms for the AQoL-6D and AQoL-8D multi-attribute utility instruments from web-based data. Qual Life Res 2016; 25: 3209-3219.

28. Lo LMP, Taylor BV, Winzenberg T, Palmer A, Blizzard L, van der Mei I (2020)

Comorbidities contribute substantially to the severity of common multiple sclerosis symptoms. J Neurol (Accepted).

29. Marrie RA. Comorbidities in Multiple Sclerosis: A Clinical Resource Guide, https://mscomorbidities.com/ (2018, accessed 17 March 2018).

30. Marrie RA, Patten SB, Tremlett H, et al. Sex differences in comorbidity at diagnosis of multiple sclerosis: A population-based study. Neurology 2016; 86: 1279-1286. DOI: https://doi.org/10.1212/WNL.0000000000002481.

31. Marrie RA, Horwitz R, Cutter G, et al. The burden of mental comorbidity in multiple sclerosis: frequent, underdiagnosed, and undertreated. Mult Scler J 2009; 15: 385-392.

32. Woolf AD and Pfleger B. Burden of major musculoskeletal conditions. Bull World Health Organ 2003; 81: 646-656.

33. Aitken D, Jones G and Winzenberg T. Clinical Overview of Osteoarthritis (OA) and the Challenges Faced for Future Management. 2019.

34. Degenhardt A, Ramagopalan SV, Scalfari A, et al. Clinical prognostic factors in multiple sclerosis: a natural history review. Nat Rev Neurol 2009; 5: 672-682. 
Table 1. The prevalence of total and doctor-diagnosed comorbidities of the AMSLS participants $(\mathrm{N}=902)$

\begin{tabular}{|c|c|c|}
\hline Comorbidities & $\begin{array}{c}\text { Total comorbidities }{ }^{\mathrm{b}} \\
\mathrm{n}(\%)\end{array}$ & $\begin{array}{c}\text { Doctor-diagnosed } \\
\text { comorbidities }^{\mathrm{c}} \\
\mathrm{n}(\%)\end{array}$ \\
\hline \multicolumn{3}{|l|}{ Mental health disorders } \\
\hline Depression & $372(41.2)$ & $303(33.6)$ \\
\hline Anxiety & $344(38.1)$ & $197(21.8)$ \\
\hline \multicolumn{3}{|l|}{ Musculoskeletal disorders } \\
\hline Osteoporosis & $124(13.8)$ & $119(13.2)$ \\
\hline Osteoarthritis & $200(22.2)$ & $182(20.2)$ \\
\hline Rheumatoid arthritis & $22(2.4)$ & $18(2.0)$ \\
\hline Systemic lupus erythematosus & $14(1.6)$ & $13(1.4)$ \\
\hline \multicolumn{3}{|l|}{ Endocrine and Metabolic diseases } \\
\hline High cholesterol & $217(24.1)$ & $214(23.7)$ \\
\hline Type 1 diabetes & $11(1.2)$ & $11(1.2)$ \\
\hline Type 2 diabetes & $47(5.2)$ & $46(5.1)$ \\
\hline Hyperthyroidism & $27(3.0)$ & $26(2.9)$ \\
\hline Hypothyroidism & $72(8.0)$ & $70(7.8)$ \\
\hline \multicolumn{3}{|l|}{ Diseases of the nervous system } \\
\hline Epilepsy & $12(1.3)$ & $8(0.9)$ \\
\hline Migraine & $243(26.9)$ & $152(16.9)$ \\
\hline \multicolumn{3}{|l|}{ Diseases of the circulatory system } \\
\hline Hypertension & $270(29.9)$ & $268(29.7)$ \\
\hline Heart diseases & $59(6.5)$ & $57(6.3)$ \\
\hline Myocardial infarction & $17(1.9)$ & $16(1.8)$ \\
\hline Stroke & $22(2.4)$ & $21(2.3)$ \\
\hline Peripheral vascular disease & $24(2.7)$ & $24(2.7)$ \\
\hline \multicolumn{3}{|l|}{ Diseases of the digestive system } \\
\hline Inflammatory bowel disease & $26(2.9)$ & $25(2.8)$ \\
\hline Coeliac disease & $13(1.4)$ & $10(1.1)$ \\
\hline Eye diseases & $135(15.0)$ & $125(13.9)$ \\
\hline Allergies & $337(37.4)$ & $257(28.5)$ \\
\hline Other autoimmune diseases & $38(4.2)$ & $35(3.9)$ \\
\hline \multicolumn{3}{|l|}{ Diseases of the skin } \\
\hline Psoriasis & $78(8.7)$ & $61(6.8)$ \\
\hline \multicolumn{3}{|l|}{ Diseases of the blood } \\
\hline Anaemia & $108(12.0)$ & $103(11.4)$ \\
\hline \multicolumn{3}{|l|}{ Neoplasms } \\
\hline Cancer & $132(14.6)$ & $130(14.4)$ \\
\hline \multicolumn{3}{|l|}{ Diseases of the genito-urinary system } \\
\hline Chronic renal disease & $12(1.3)$ & $12(1.3)$ \\
\hline
\end{tabular}


Table 2. Characteristics of the AMSLS ${ }^{\text {a }}$ participants

\begin{tabular}{|c|c|}
\hline Characteristic & $\begin{array}{c}\text { Study sample } \\
(\mathrm{N}=902)\end{array}$ \\
\hline Age (years), mean (SD) & $55.8(11.4)$ \\
\hline Years since MS diagnosis, mean (SD) & $15.4(9.3)$ \\
\hline Female, n $(\%)$ & 709 (78.6) \\
\hline Currently on Disease Modifying Therapy, n (\%) & $565(62.6)$ \\
\hline \multicolumn{2}{|l|}{ MS onset-type ${ }^{\mathrm{b}}, \mathrm{n}(\%)$} \\
\hline Relapse-onset Multiple Sclerosis ${ }^{c}$ & $661(87.4)$ \\
\hline Progressive-onset Multiple Sclerosis ${ }^{d}$ & $95(12.6)$ \\
\hline \multicolumn{2}{|l|}{ Education attainment, $\mathrm{n}(\%)$} \\
\hline Secondary school or less & $298(33.3)$ \\
\hline Occupational certificate/Diploma & $249(27.8)$ \\
\hline University degree and higher & $348(38.9)$ \\
\hline \multicolumn{2}{|l|}{ Body mass index ${ }^{\mathrm{e}}\left(\mathrm{kg} / \mathrm{m}^{2}\right), \mathrm{n}(\%)$} \\
\hline Normal $(B M I=18.5$ to 25$)$ & $368(42.2)$ \\
\hline Overweight $(B M I=25$ to 30$)$ & $279(32.0)$ \\
\hline Obese (BMI = 30 and over $)$ & $226(25.9)$ \\
\hline AQoL-8D's psychosocial super-dimension score ${ }^{\mathrm{f}}$, mean (SD) & $0.34(0.19)$ \\
\hline AQoL-8D's physical super-dimension score ${ }^{\mathrm{f}}$, mean (SD) & $0.58(0.22)$ \\
\hline Overall AQoL-8D score ${ }^{\mathrm{f}}$, mean (SD) & $0.62(0.21)$ \\
\hline
\end{tabular}

${ }^{a}$ Australian MS Longitudinal Study; ${ }^{b}$ Excluded those who ticked "unsure" $(n=103)$ and those who did not specify their MS onset type $(\mathrm{n}=43)$; ${ }^{\mathrm{c}}$ Includes relapsing remitting multiple sclerosis and secondary progressive multiple sclerosis; ${ }^{\mathrm{d}}$ Includes primary progressive multiple sclerosis and progressive relapsing multiple sclerosis; ${ }^{\mathrm{e}}$ Body mass index (BMI) was calculated by dividing self-reported weight (in kilograms) by height ${ }^{2}$ (in centimetres); ${ }^{\mathrm{f}} \mathrm{AQoL}-8 \mathrm{D}$ ranged from 0 (death/worst health state) to 1 (perfect health). 
Table 3. Associations between the number of comorbidities and the overall AQoL-8D, AQoL-8D's psychosocial and physical super-dimensions

\begin{tabular}{|c|c|c|c|c|c|c|}
\hline & & & \multicolumn{2}{|c|}{ Overall AQoL-8D } & $\begin{array}{c}\text { AQoL-8D's } \\
\text { psychosocial super- } \\
\text { dimension }\end{array}$ & $\begin{array}{l}\text { AQoL-8D's physical super- } \\
\text { dimension }\end{array}$ \\
\hline $\begin{array}{l}\text { Number of } \\
\text { comorbidities }\end{array}$ & $\mathrm{n}(\%)$ & $\begin{array}{l}\text { Predicted Mean } \\
\quad(95 \% \mathrm{CI})\end{array}$ & $\begin{array}{c}\text { Unadjusted } \\
\text { coefficients } \\
(95 \% \mathrm{CI}) \\
\end{array}$ & $\begin{array}{c}\text { Adjusted } \\
\text { coefficients } \\
(95 \% \mathrm{CI})^{\mathrm{a}} \\
\end{array}$ & $\begin{array}{l}\text { Adjusted coefficients } \\
\qquad(95 \% \mathrm{CI})^{\mathrm{a}}\end{array}$ & $\begin{array}{l}\text { Adjusted coefficients } \\
\qquad(95 \% \mathrm{CI})^{\mathrm{a}}\end{array}$ \\
\hline \multicolumn{7}{|c|}{ Total comorbidities $^{b}$} \\
\hline 0 & $81(8.98)$ & $0.73(0.69,0.77)$ & & & Reference & \\
\hline 1 & $122(13.53)$ & $0.71(0.68,0.75)$ & $-0.02(-0.07,0.04)$ & $-0.02(-0.08,0.04)$ & $-0.02(-0.08,0.03)$ & $-0.03(-0.08,0.03)$ \\
\hline $2-3$ & $329(36.47)$ & $0.65(0.62,0.67)$ & $-0.08(-0.13,-0.03)$ & $-0.09(-0.14,-0.04)$ & $-0.10(-0.14,-0.05)$ & $-0.08(-0.13,-0.03)$ \\
\hline 4 or more & $370(41.02)$ & $0.55(0.53,0.57)$ & $-0.18(-0.23,-0.13)$ & $-0.19(-0.24,-0.14)$ & $-0.17(-0.21,-0.13)$ & $-0.16(-0.21,-0.11)$ \\
\hline Trend: & & & $p<0.01$ & $p<0.01$ & $p<0.01$ & $p<0.01$ \\
\hline \multicolumn{7}{|c|}{ Doctor-diagnosed comorbidities ${ }^{c}$} \\
\hline 0 & $122(13.53)$ & $0.71(0.67,0.75)$ & & & Reference & \\
\hline 1 & $175(19.40)$ & $0.67(0.64,0.71)$ & $-0.03(-0.08,0.01)$ & $-0.04(-0.09,0.01)$ & $-0.06(-0.10,-0.01)$ & $-0.03(-0.07,0.02)$ \\
\hline $2-3$ & $325(36.03)$ & $0.64(0.61,0.66)$ & $-0.07(-0.12,-0.03)$ & $-0.09(-0.13,-0.04)$ & $-0.09(-0.13,-0.05)$ & $-0.07(-0.11-0.03)$ \\
\hline 4 or more & $280(31.04)$ & $0.54(0.51,0.56)$ & $-0.17(-0.12,-0.13)$ & $-0.19(-0.23,-0.14)$ & $-0.16(-0.20,-0.12)$ & $-0.16(-0.20,-0.12)$ \\
\hline Trend: & & & $p<0.01$ & $p<0.01$ & $p<0.01$ & $p<0.01$ \\
\hline
\end{tabular}


Impact of comorbidities on HRQoL in MS

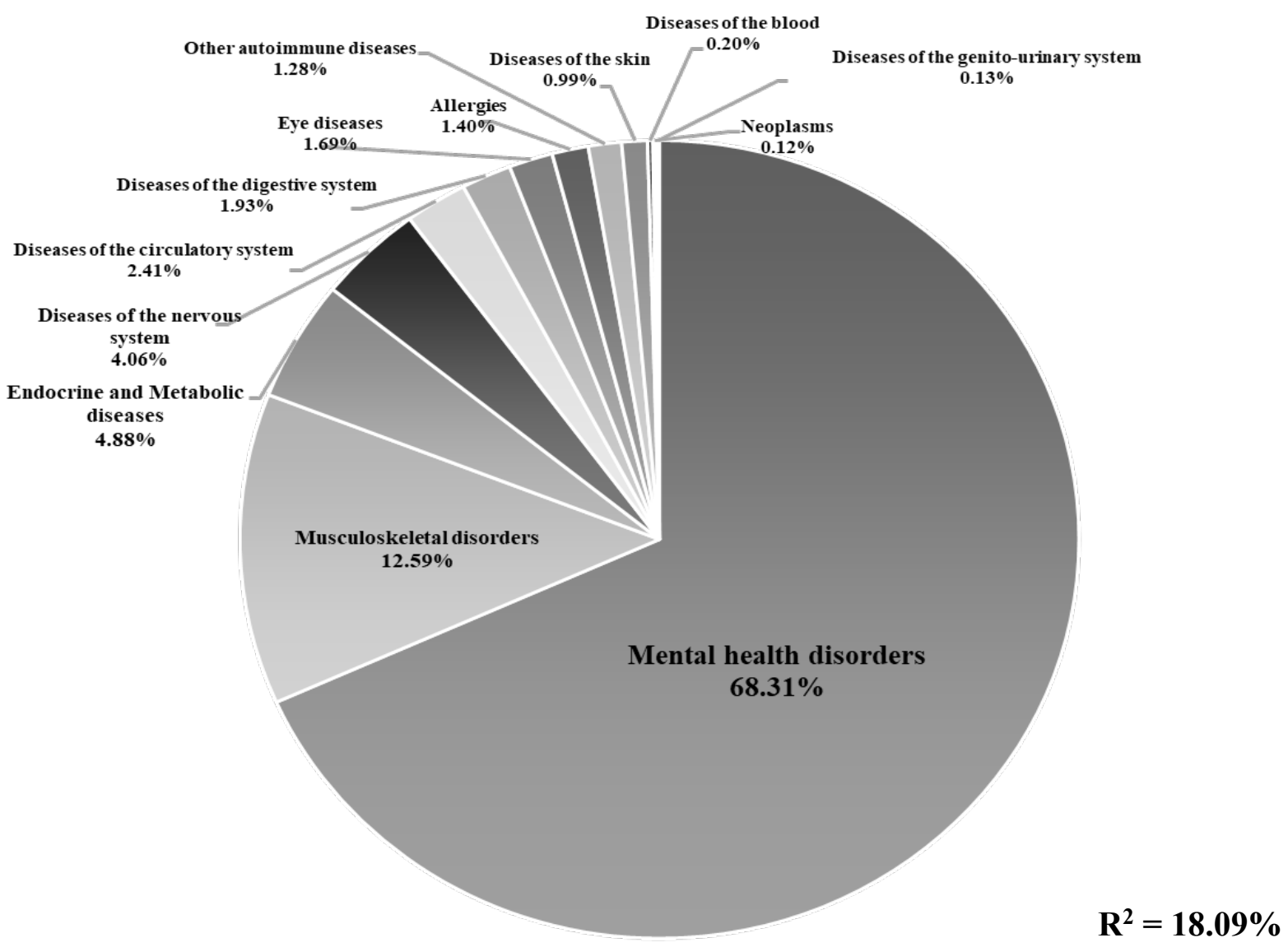

A. OVERALL AQoL-8D

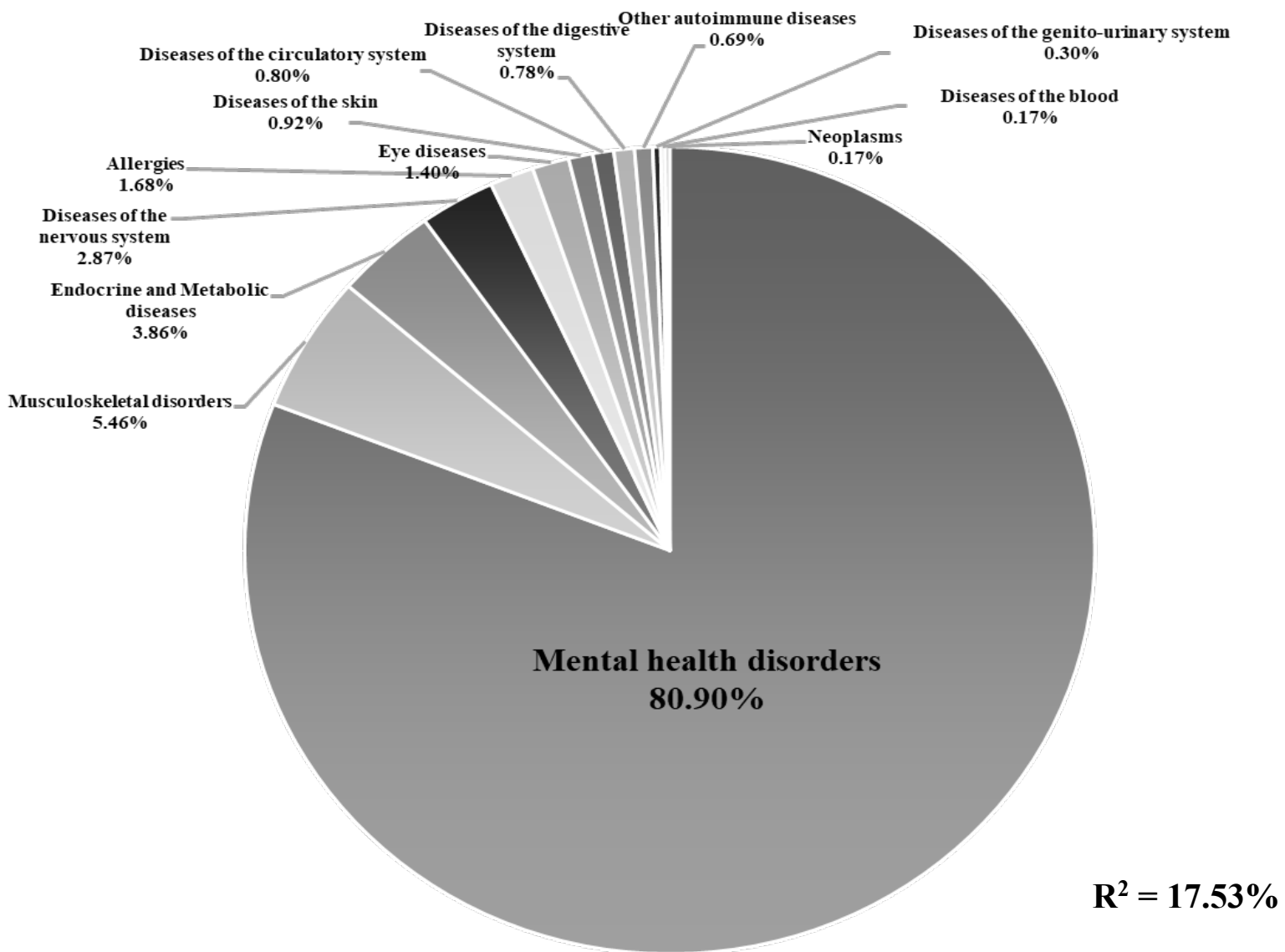

B. AQoL-8D's Psychosocial Super-dimension 


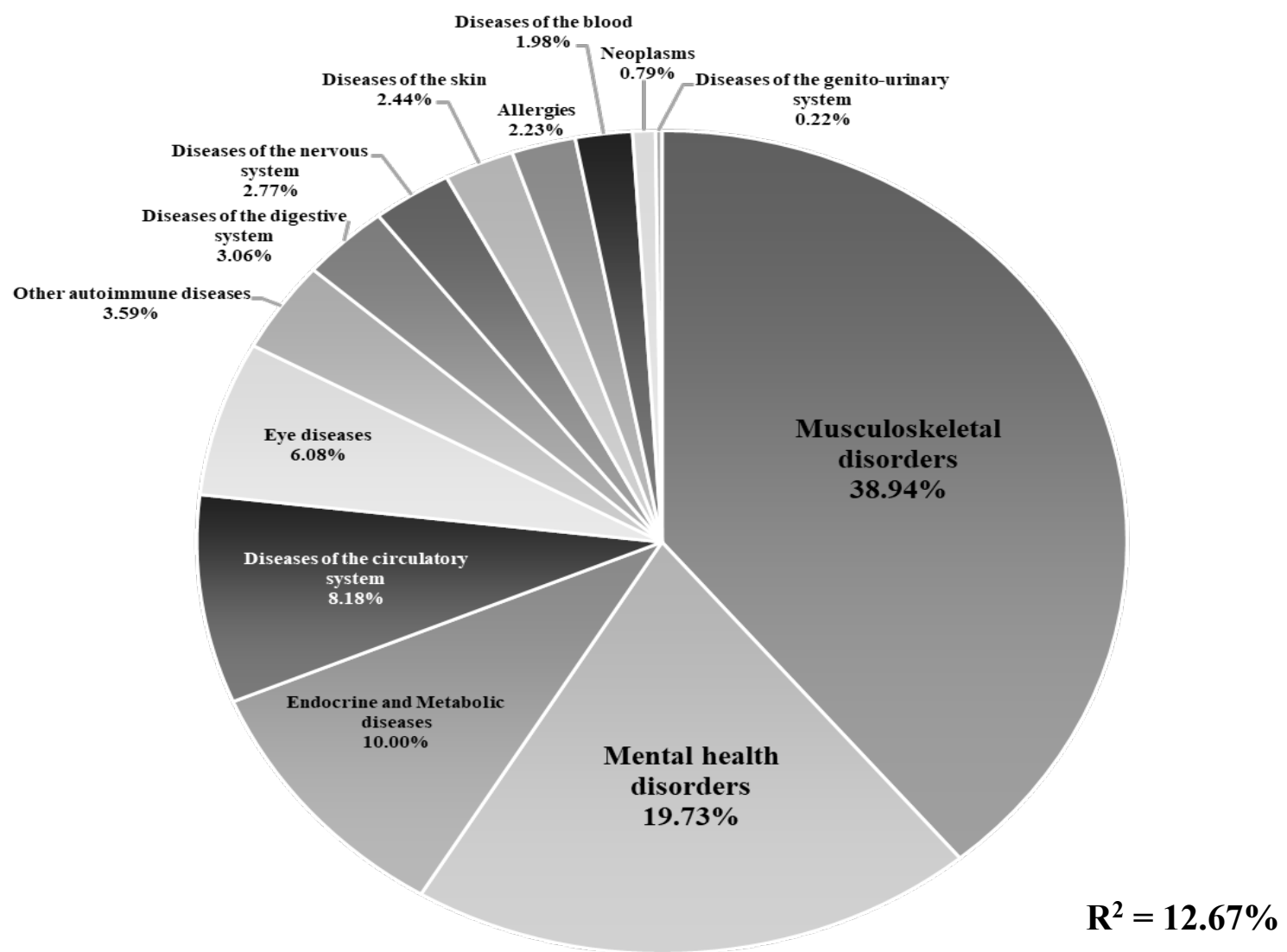

C. AQoL-8D's Physical Super-dimension

Figure 1. The relative contribution (\%) ${ }^{\mathrm{a}}$ of the 13 comorbidity groups ${ }^{\mathrm{b}}$ based on total comorbidities $^{\mathrm{c}}$ to the overall AQoL-8D (panel A), AQoL-8D's psychosocial (panel B) and physical (panel C) superdimensions.

${ }^{\text {a }}$ The values were calculated using general dominance analysis and were obtained from the individual standardized weight (out of $100 \%$ ) of the variance of each comorbidity groups over the total variance of the overall AQoL-8D $\left(\mathrm{R}^{2}=18.09\right)$; AQoL-8D's psychosocial $\left(\mathrm{R}^{2}=17.53\right)$ and physical $\left(\mathrm{R}^{2}=12.67\right)$ super-dimensions of the multivariable regression model; ${ }^{\mathrm{b}}$ The 13 comorbidity groups were grouped according to the 263 blocks (disease categories) in the International Classification of Diseases- $10^{\text {th }}$ revision (ICD-10) structure; ${ }^{\mathrm{c}}$ Total comorbidities refer to any comorbidity the participant reported having.

AQoL-8D: Assessment of Quality of Life with eight dimensions. 
Impact of comorbidities on HRQoL of people with MS

Table 4. Associations between total comorbidities ${ }^{a}$ and overall AQoL-8D people with MS

\begin{tabular}{|c|c|c|c|}
\hline & $\begin{array}{l}\text { Predicted mean } \\
\quad(95 \% \mathrm{CI})\end{array}$ & $\begin{array}{l}\text { Adjusted coefficients } \\
\quad(\beta, 95 \% \mathrm{CI})^{\mathrm{b}}\end{array}$ & R-squared $(\%)^{\mathrm{c}}$ \\
\hline $\begin{array}{l}\text { Total variance of the multiple regression } \\
\text { model (incl. } 13 \text { comorbidity groups) }\end{array}$ & & & 18.09 \\
\hline $\begin{array}{l}\text { Predicted AQoL-8D of those without } \\
\text { comorbidities (Reference) }\end{array}$ & $0.74(0.69,0.78)$ & & \\
\hline \multicolumn{4}{|l|}{$\begin{array}{c}\text { Comorbidity groups and individual } \\
\text { comorbidities }\end{array}$} \\
\hline Mental health disorders & & & 12.35 \\
\hline Depression & $0.58(0.53,0.63)$ & $-0.15(-0.18,-0.13)$ & \\
\hline Anxiety & $0.63(0.57,0.67)$ & $-0.11(-0.14,-0.08)$ & \\
\hline Musculoskeletal disorders & & & 2.28 \\
\hline Osteoporosis & $0.66(0.60,0.72)$ & $-0.08(-0.12,-0.04)$ & \\
\hline Osteoarthritis & $0.68(0.63,0.74)$ & $-0.05(-0.09,-0.02)$ & \\
\hline Rheumatoid arthritis & $0.64(0.54,0.74)$ & $-0.09(-0.18,-0.01)$ & \\
\hline Systemic lupus erythematosus & $0.57(0.45,0.69)$ & $-0.16(-0.27,-0.05)$ & \\
\hline Endocrine and Metabolic diseases & & & 0.88 \\
\hline High cholesterol & $0.73(0.67,0.78)$ & $-0.01(-0.04,0.03)$ & \\
\hline Type 1 diabetes & $0.64(0.50,0.78)$ & $-0.09(-0.22,0.03)$ & \\
\hline Type 2 diabetes & $0.66(0.58,0.74)$ & $-0.08(-0.14,-0.01)$ & \\
\hline Hyperthyroidism & $0.61(0.52,0.70)$ & $-0.12(-0.20,-0.04)$ & \\
\hline Hypothyroidism & $0.69(0.62,0.76)$ & $-0.04(-0.09,0.01)$ & \\
\hline Diseases of the nervous system & & & 0.73 \\
\hline Epilepsy & $0.64(0.51,0.76)$ & $-0.10(-0.21,0.02)$ & \\
\hline Migraine & $0.69(0.63,0.74)$ & $-0.05(-0.08,-0.01)$ & \\
\hline Diseases of the circulatory system & & & 0.44 \\
\hline Hypertension & $0.73(0.67,0.78)$ & $-0.01(-0.04,0.02)$ & \\
\hline Heart diseases & $0.68(0.60,0.75)$ & $-0.06(-0.12,-0.01)$ & \\
\hline Myocardial infarction & $0.74(0.63,0.85)$ & $0.00(-0.09,0.11)$ & \\
\hline Stroke & $0.70(0.60,0.80)$ & $-0.03(-0.12,0.06)$ & \\
\hline Peripheral vascular disease & $0.66(0.57,0.76)$ & $-0.07(-0.16,0.01)$ & \\
\hline Diseases of the digestive system & & & 0.35 \\
\hline Inflammatory bowel disease & $0.63(0.54,0.72)$ & $-0.10(-0.18,-0.02)$ & \\
\hline Coeliac disease & $0.72(0.60,0.84)$ & $-0.01(-0.12,0.10)$ & \\
\hline Eye diseases & $0.70(0.64,0.76)$ & $-0.03(-0.07,0.01)$ & 0.31 \\
\hline Allergies & $0.70(0.65,0.75)$ & $-0.03(-0.06,-0.01)$ & 0.25 \\
\hline Other autoimmune diseases & $0.66(0.58,0.74)$ & $-0.07(-0.14,-0.01)$ & 0.23 \\
\hline Diseases of the skin & & & 0.18 \\
\hline Psoriasis & $0.70(0.63,0.76)$ & $-0.04(-0.09,0.01)$ & \\
\hline Diseases of the blood & & & 0.04 \\
\hline Anaemia & $0.72(0.65,0.77)$ & $-0.02(-0.06,0.03)$ & \\
\hline Neoplasms & & & 0.02 \\
\hline Cancer & $0.73(0.66,0.78)$ & $-0.01(-0.05,0.03)$ & \\
\hline Diseases of the genito-urinary system & & & 0.02 \\
\hline Chronic renal disease & $0.67(0.54,0.80)$ & $-0.07(-0.19,0.06)$ & \\
\hline
\end{tabular}

\footnotetext{
${ }^{a}$ Total comorbidities refer to any comorbidity the participant reported having.

${ }^{\mathrm{b}}$ Estimated decrease in health-related quality of life that is associated with having the individual comorbidity. The values were adjusted for age, sex and education attainment. Bold font indicates statistical significance at $95 \%$ confidence interval $(\mathrm{CI}){ }^{\mathrm{c}}$ The R-squared $\left(\% \mathrm{R}^{2}\right)$ value is the total variance from the multiple regression model and the individual variance contributed by each comorbidity group to the to the total variance as obtained from the general dominance analysis. AQoL-8D: Assessment of Quality of Life with eight dimensions.
} 
Table 5. Associations between total comorbidities ${ }^{a}$ and the AQoL-8D's psychosocial and physical super-dimensions

\begin{tabular}{|c|c|c|c|c|c|c|}
\hline \multirow[t]{2}{*}{ Super-dimensions } & \multicolumn{3}{|c|}{ AQoL-8D's psychosocial super-dimension } & \multicolumn{3}{|c|}{ AQoL-8D's physical super-dimension } \\
\hline & $\begin{array}{l}\text { Predicted mean } \\
\quad(95 \% \mathrm{CI})\end{array}$ & $\begin{array}{l}\text { Adjusted coefficients } \\
\qquad(\beta, 95 \% \mathrm{CI})^{\mathrm{b}}\end{array}$ & $\begin{array}{l}\text { R-squared } \\
(\%)^{\mathrm{c}}\end{array}$ & $\begin{array}{l}\text { Predicted mean } \\
\quad(95 \% \mathrm{CI})\end{array}$ & $\begin{array}{l}\text { Adjusted coefficients } \\
\qquad(\beta, 95 \% \mathrm{CI})^{\mathrm{b}}\end{array}$ & $\begin{array}{l}\text { R-squared } \\
(\%)^{\mathrm{c}}\end{array}$ \\
\hline $\begin{array}{l}\text { Total variance of the multiple regression } \\
\text { model (incl. } 13 \text { comorbidity groups) }\end{array}$ & & & $\mathbf{1 7 . 5 3}$ & & & 12.67 \\
\hline $\begin{array}{l}\text { Predicted AQoL-8D of those without } \\
\text { comorbidities (Reference) }\end{array}$ & $0.45(0.41,0.49)$ & & & $0.68(0.64,0.72)$ & & \\
\hline \multicolumn{7}{|l|}{$\begin{array}{l}\text { Comorbidity groups and individual } \\
\text { comorbidities }\end{array}$} \\
\hline Mental health disorders & & & 14.18 & & & 2.50 \\
\hline Depression & $0.30(0.26,0.35)$ & $-0.14(-0.16,-0.11)$ & & $0.58(0.53,0.63)$ & $-0.10(-0.12,-0.07)$ & \\
\hline Anxiety & $0.34(0.29,0.39)$ & $-0.10(-0.13,-0.07)$ & & $0.62(0.56,0.67)$ & $-0.06(-0.09,-0.03)$ & \\
\hline Musculoskeletal disorders & & & 0.96 & & & 4.93 \\
\hline Osteoporosis & $0.39(0.33,0.44)$ & $-0.06(-0.10,-0.02)$ & & $0.62(0.56,0.68)$ & $-0.06(-0.10,-0.02)$ & \\
\hline Osteoarthritis & $0.42(0.37,0.47)$ & $-0.03(-0.06,0.01)$ & & $0.61(0.56,0.67)$ & $-0.07(-0.10,-0.04)$ & \\
\hline Rheumatoid arthritis & $0.40(0.31,0.49)$ & $-0.05(-0.13,0.03)$ & & $0.57(0.48,0.67)$ & $-0.11(-0.19,-0.02)$ & \\
\hline Systemic lupus erythematosus & $0.35(0.24,0.46)$ & $-0.09(-0.19,0.01)$ & & $0.50(0.38,0.61)$ & $-0.18(-0.29,-0.07)$ & \\
\hline Endocrine and Metabolic diseases & & & 0.68 & & & 1.27 \\
\hline High cholesterol & $0.44(0.39,0.49)$ & $-0.01(-0.04,0.02)$ & & $0.67(0.61,0.73)$ & $-0.01(-0.04,0.03)$ & \\
\hline Type 1 diabetes & $0.38(0.25,0.51)$ & $-0.07(-0.19,0.05)$ & & $0.60(0.46,0.73)$ & $-0.08(-0.21,0.04)$ & \\
\hline Type 2 diabetes & $0.37(0.31,0.44)$ & $-0.07(-0.13,-0.01)$ & & $0.64(0.57,0.72)$ & $-0.04(-0.09,0.03)$ & \\
\hline Hyperthyroidism & $0.35(0.27,0.43)$ & $-0.09(-0.16,-0.02)$ & & $0.57(0.48,0.66)$ & $-0.11(-0.19,-0.03)$ & \\
\hline Hypothyroidism & $0.41(0.35,0.48)$ & $-0.03(-0.08,0.02)$ & & $0.64(0.57,0.70)$ & $-0.04(-0.09,0.01)$ & \\
\hline Diseases of the nervous system & & & 0.50 & & & 0.35 \\
\hline Epilepsy & $0.38(0.27,0.50)$ & $-0.06,(-0.17,0.04)$ & & $0.57(0.45,0.69)$ & $-0.11(-0.22,0.01)$ & \\
\hline Migraine & $0.41(0.36,0.46)$ & $-0.03(-0.06,-0.01)$ & & $0.63(0.58,0.69)$ & $-0.05(-0.08,-0.02)$ & \\
\hline
\end{tabular}


Diseases of the circulatory system

Hypertension

Heart diseases

Myocardial infarction

Stroke

Peripheral vascular disease

Diseases of the digestive system

Inflammatory bowel disease

Coeliac disease

Eye diseases

Allergies

Other autoimmune diseases

Diseases of the skin

Psoriasis

Diseases of the blood

Anaemia

Neoplasms

Cancer

Diseases of the genito-urinary system

Chronic renal disease

$$
\begin{aligned}
& 0.44(0.39,0.49) \\
& 0.41(0.34,0.47) \\
& 0.45(0.36,0.56) \\
& 0.43(0.34,0.52) \\
& 0.40(0.32,0.49)
\end{aligned}
$$

$0.37(0.28,0.45)$

$0.49(0.38,0.60)$

$0.41(0.36,0.47)$

$0.42(0.37,0.47)$

$0.40(0.33,0.47)$

$0.42(0.36,0.48)$

$0.44(0.38,0.50)$

$0.44(0.38,0.49)$

$0.37(0.25,0.49)$
0.14

$-0.01(-0.03,0.02)$

$-0.04(-0.09,0.01)$

$0.00(-0.08,0.10)$

$-0.01(-0.10,0.07)$

$-0.04(-0.12,0.04)$

0.14

\section{$\mathbf{- 0 . 0 8}(\mathbf{- 0 . 1 5}, \mathbf{- 0 . 0 1})$}

$0.04(-0.06,0.15)$

$-0.03(-0.07,0.01)$

$-0.02(-0.05,0.01)$

$-0.04(-0.10,0.02)$

$-0.03(-0.07,0.01)$

$-0.01(-0.04,0.03)$

$-0.01(-0.04,0.03)$

0.05

$-0.07(-0.18,0.04)$

0.03

0.03

$\begin{array}{ll}0.68(0.62,0.73) & 0.00(-0.03,0.03) \\ 0.64(0.57,0.71) & -0.04(-0.09,0.02) \\ 0.67(0.56,0.78) & -0.01(-0.11,0.09) \\ 0.62(0.53,0.72) & -0.05(-0.14,0.03) \\ 0.62(0.52,0.71) & -0.06(-0.14,0.02)\end{array}$

$0.57(0.48,0.67)$

$0.67(0.55,0.79)$

$\mathbf{- 0 . 1 0}(\mathbf{- 0 . 1 8 ,} \mathbf{- 0 . 0 3})$

$-0.01(-0.11,0.11)$

$-0.02(-0.06,0.02)$

$0.64(0.58,0.69)$

$\mathbf{- 0 . 0 4}(-0.07,-0.01)$

$-0.10(-0.17,-0.04)$

$0.57(0.49,0.65)$

$0.63(0.56,0.69)$

$-0.05(-0.10,-0.01)$

$0.67(0.61,0.73)$

$-0.01(-0.05,0.03)$

$0.68(0.62,0.73)$

$-0.01(-0.04,0.04)$
0.77

.04

$0.65(0.52,0.78) \quad-0.03(-0.15,0.09)$

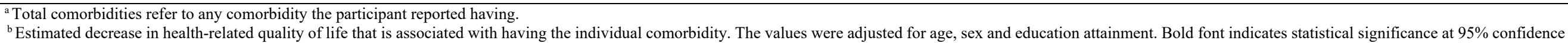

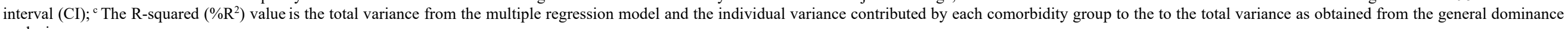
analysis.

AQoL-8D: Assessment of Quality of Life with eight dimensions 
Impact of comorbidities on HRQoL of people with MS

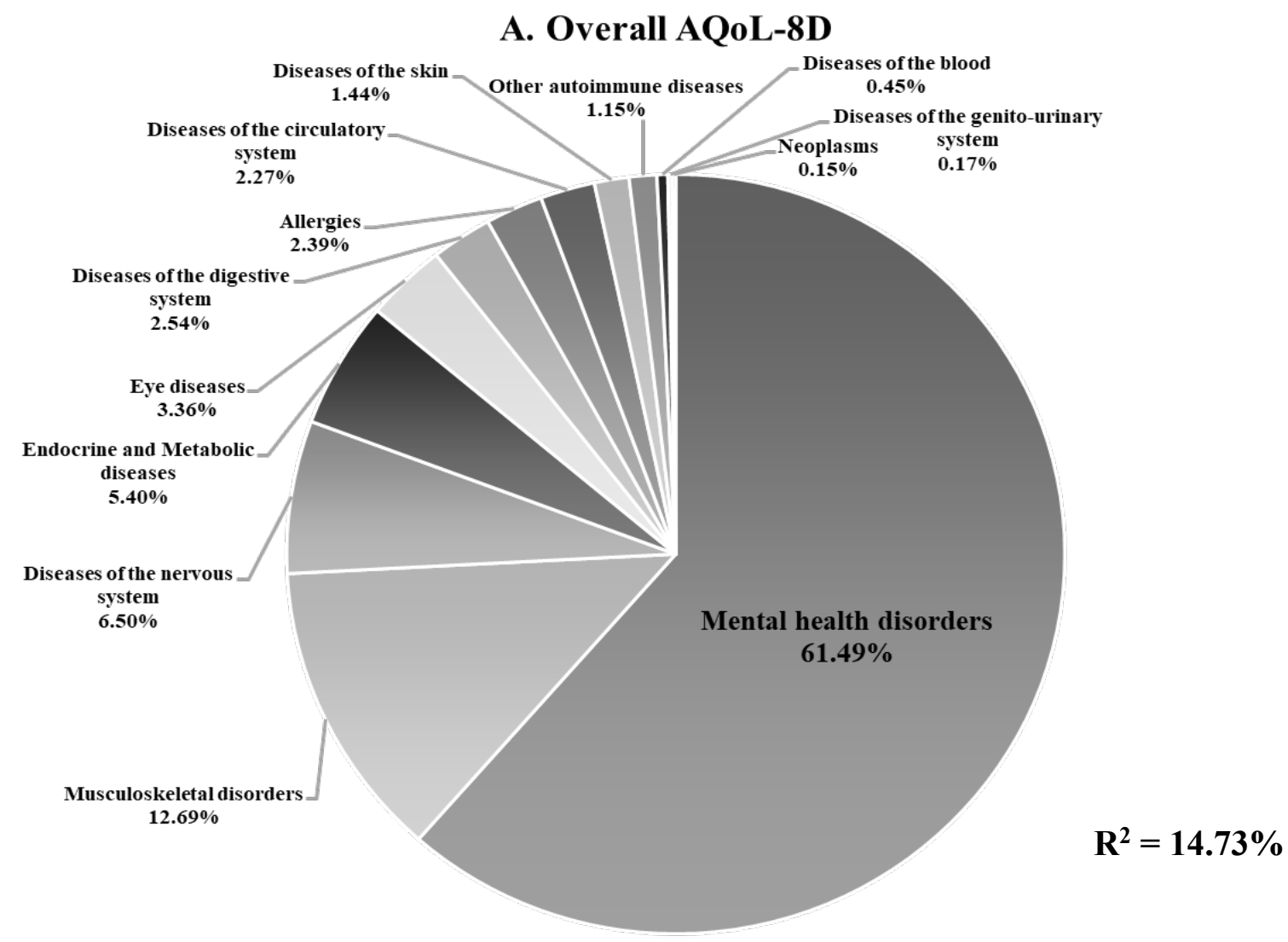

\section{B. AQoL-8D's Psychosocial Super-dimension}

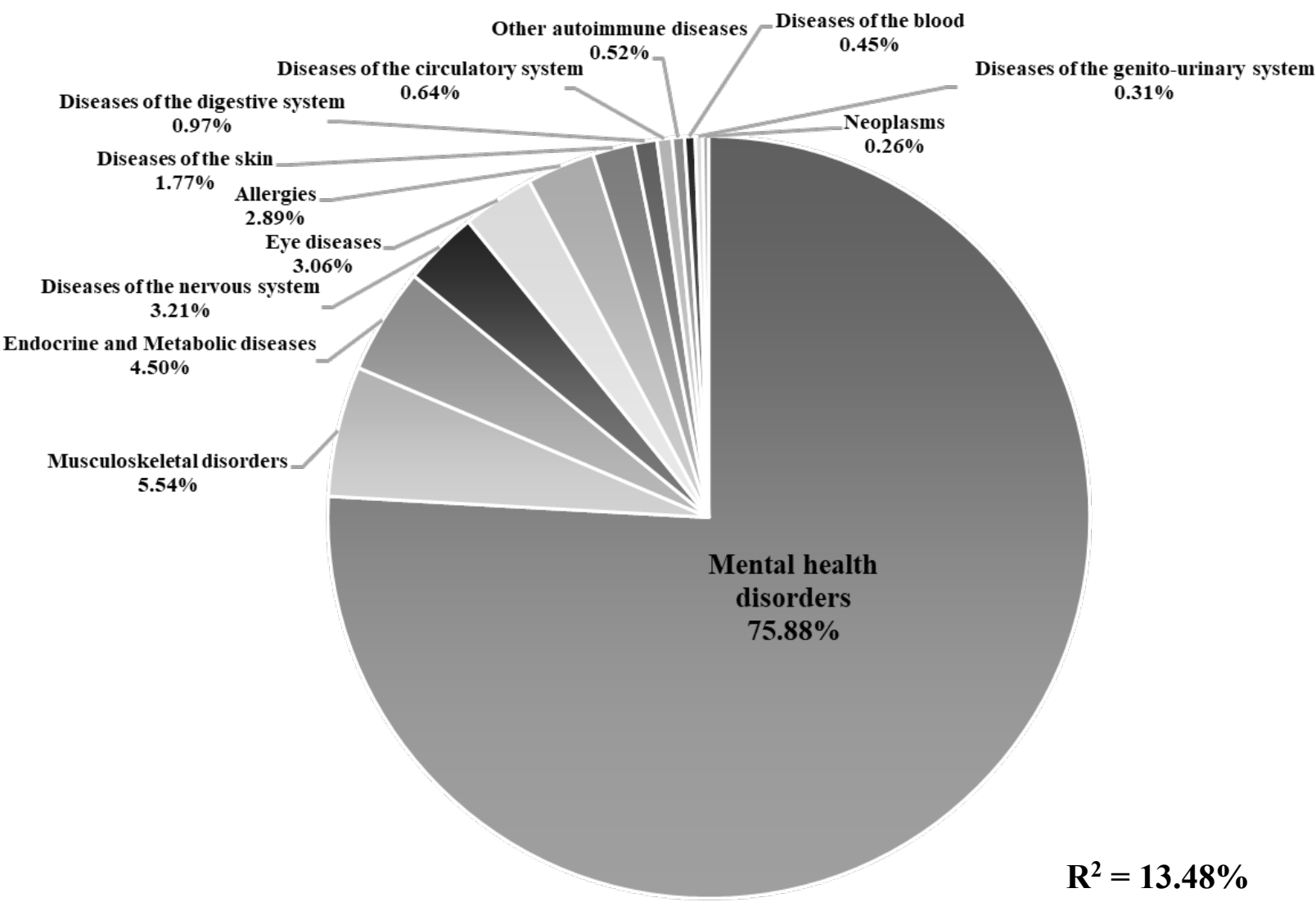




\section{AQoL-8D's Physical Super-dimension}

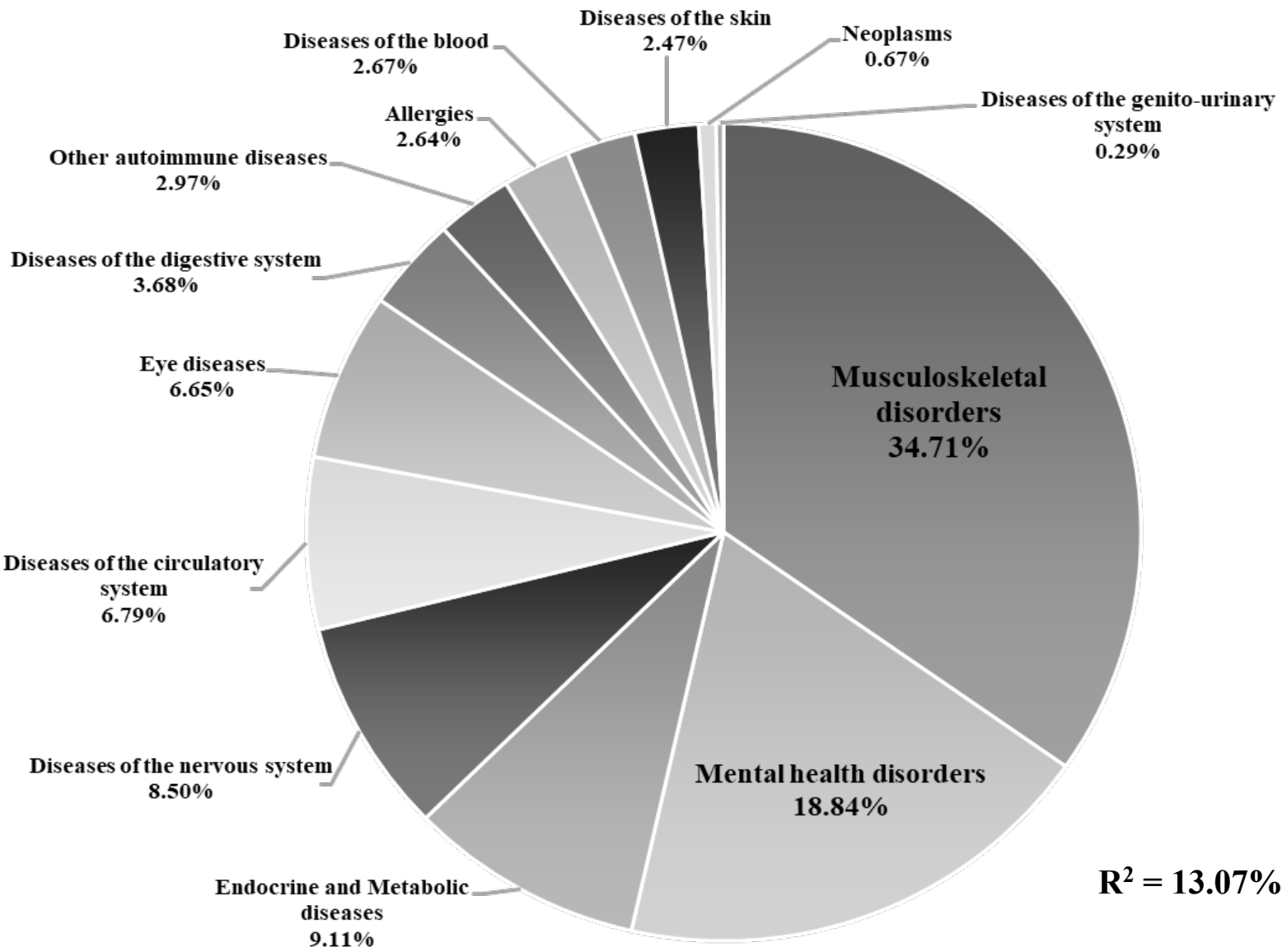

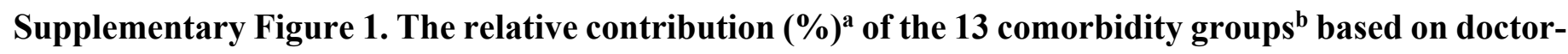
diagnosed comorbidities ${ }^{\mathrm{c}}$ to the overall AQoL-8D (panel A), AQoL-8D's psychosocial (panel B) and physical (panel C) super-dimensions.

${ }^{\text {a }}$ The values were calculated using general dominance analysis and were obtained from the individual standardized weight (out of $100 \%$ ) of the variance of each comorbidity groups over the total variance of the overall AQoL-8D $\left(\mathrm{R}^{2}=14.73\right)$; AQoL-8D's psychosocial $\left(\mathrm{R}^{2}=13.07\right)$ and physical $\left(\mathrm{R}^{2}=13.48\right)$ super-dimensions of the multivariable regression model; ${ }^{\mathrm{b}}$ The 13 comorbidity groups were grouped to the 263 blocks (disease categories) in the International Classification of Diseases$10^{\text {th }}$ revision (ICD-10) structure; ${ }^{\mathrm{c}}$ Doctor-diagnosed comorbidities refer to any comorbidity the patient reported as diagnosed by a doctor.

AQoL-8D: Assessment of Quality of Life with eight dimensions. 
Impact of comorbidities on HRQoL of people with MS

Supplementary Table 1. Associations between doctor-diagnosed comorbidities ${ }^{\text {a }}$ and overall AQoL-8D of people with MS

\begin{tabular}{|c|c|c|c|}
\hline & $\begin{array}{l}\text { Predicted mean } \\
\quad(95 \% \mathrm{CI})\end{array}$ & $\begin{array}{l}\text { Adjusted coefficients } \\
\qquad(\beta, 95 \% \mathrm{CI})^{\mathrm{b}}\end{array}$ & R-squared $(\%)^{\mathrm{c}}$ \\
\hline $\begin{array}{l}\text { Total variance of the multiple regression } \\
\text { model (incl. } 13 \text { comorbidity groups) }\end{array}$ & & & 14.73 \\
\hline $\begin{array}{l}\text { Predicted AQoL-8D of those without } \\
\text { comorbidities (Reference) }\end{array}$ & $0.72(0.69,0.76)$ & & \\
\hline \multicolumn{4}{|l|}{$\begin{array}{c}\text { Comorbidity groups and individual } \\
\text { comorbidities }\end{array}$} \\
\hline Mental health disorders & & & 9.06 \\
\hline Depression & $0.58(0.53,0.62)$ & $-0.14(-0.17,-0.11)$ & \\
\hline Anxiety & $0.61(0.56,0.66)$ & $-0.10(-0.14,-0.07)$ & \\
\hline Diseases of the musculoskeletal system & & & 1.87 \\
\hline Osteoporosis & $0.65(0.59,0,70)$ & $-0.07(-0.12,-0.03)$ & \\
\hline Osteoarthritis & $0.67(0.62,0.72)$ & $-0.05(-0.09,-0.02)$ & \\
\hline Rheumatoid arthritis & $0.65(0.55,0.75)$ & $-0.07(-0.16,0.03)$ & \\
\hline Systemic lupus erythematosus & $0.58(0.46,0.70)$ & $-0.14(-0.25,-0.02)$ & \\
\hline Endocrine and Metabolic diseases & & & 0.80 \\
\hline High cholesterol & $0.72(0.67,0.77)$ & $0.00(-0.03,0.03)$ & \\
\hline Type 1 diabetes & $0.63(0.50,0.76)$ & $-0.09(-0.22,0.04)$ & \\
\hline Type 2 diabetes & $0.65(0.58,0.73)$ & $0.06(-0.13,-0.01)$ & \\
\hline Hyperthyroidism & $0.61(0.52,0.70)$ & $-0.11(-0.19,-0.03)$ & \\
\hline Hypothyroidism & $0.68(0.62,0.75)$ & $-0.04(-0.09,0.02)$ & \\
\hline Diseases of the nervous system & & & 0.96 \\
\hline Epilepsy & $0.65(0.50,0.80)$ & $-0.07(-0.21,0.07)$ & \\
\hline Migraine & $0.65(0.60,0.70)$ & $-0.07(-0.10,-0.03)$ & \\
\hline Diseases of the circulatory system & & & 0.33 \\
\hline Hypertension & $0.71(0.67,0.76)$ & $-0.01(-0.04,0.03)$ & \\
\hline Heart diseases & $0.67(0.60,0.73)$ & $-0.05(-0.11,0.01)$ & \\
\hline Myocardial infarction & $0.72(0.62,0.83)$ & $0.00(-0.10,0.11)$ & \\
\hline Stroke & $0.69(0.59,0.79)$ & $-0.03(-0.12,0.06)$ & \\
\hline Peripheral vascular disease & $0.65(0.56,0.74)$ & $-0.07(-0.15,0.02)$ & \\
\hline Diseases of the digestive system & & & 0.37 \\
\hline Inflammatory bowel disease & $0.63(0.54,0.72)$ & $-0.08(-0.17,-0.01)$ & \\
\hline Coeliac disease & $0.67(0.53,0.80)$ & $-0.05(-0.18,0.08)$ & \\
\hline Eye diseases & $0.68(0.63,0.74)$ & $-0.04(-0.08,0.01)$ & 0.50 \\
\hline Allergies & $0.68(0.63,0.73)$ & $-0.03(-0.07,-0.01)$ & 0.35 \\
\hline Other autoimmune diseases & $0.65(0.57,0.73)$ & $-0.06(-0.13,0.01)$ & 0.17 \\
\hline Diseases of the skin & & & 0.21 \\
\hline Psoriasis & $0.68(0.61,0.75)$ & $-0.04(-0.09,0.02)$ & \\
\hline Diseases of the blood & & & 0.07 \\
\hline Anaemia & $0.72(0.66,0.78)$ & $0.00(-0.04,0.04)$ & \\
\hline Neoplasms & & & 0.02 \\
\hline Cancer & $0.72(0.66,0.77)$ & $0.00(-0.04,0.04)$ & \\
\hline Diseases of the genito-urinary system & & & 0.03 \\
\hline Chronic renal disease & $0.65(0.53,0.78)$ & $-0.06(-0.18,0.06)$ & \\
\hline
\end{tabular}

\footnotetext{
${ }^{a}$ Doctor-diagnosed comorbidities refer to any comorbidity the patient reported as diagnosed by a doctor.

${ }^{\mathrm{b}}$ Estimated decrease in health-related quality of life that is associated with having the individual comorbidity. The values were adjusted for age, sex and education attainment. Bold font indicates statistical significance at $95 \%$ confidence interval $(\mathrm{CI}){ }^{\mathrm{c}}$ The $\mathrm{R}$-squared $\left(\% \mathrm{R}^{2}\right)$ value is the total variance from the multiple regression model and the individual variance contributed by each comorbidity group to the to the total variance as obtained from the general dominance analysis.

AQoL-8D: Assessment of Quality of Life with eight dimensions.
} 
Supplementary Table 2. Association between doctor-diagnosed comorbidities ${ }^{\mathrm{a}}$ and the AQoL-8D's psychosocial and physical super-dimensions

\begin{tabular}{|c|c|c|c|c|c|c|}
\hline \multirow[t]{2}{*}{ Super-dimensions } & \multicolumn{3}{|c|}{ AQoL-8D's psychosocial super-dimensions } & \multicolumn{3}{|c|}{ AQoL-8D's physical super-dimensions } \\
\hline & $\begin{array}{l}\text { Predicted mean } \\
\quad(95 \% \mathrm{CI})\end{array}$ & $\begin{array}{l}\text { Adjusted coefficients } \\
\qquad(\beta, 95 \% \mathrm{CI})^{\mathrm{b}}\end{array}$ & $\begin{array}{l}\text { R-squared } \\
(\%)^{c}\end{array}$ & $\begin{array}{l}\text { Predicted mean } \\
\quad(95 \% \mathrm{CI})\end{array}$ & $\begin{array}{l}\text { Adjusted coefficients } \\
\qquad(\beta, 95 \% \mathrm{CI})^{\mathrm{b}}\end{array}$ & $\begin{array}{l}\text { R-squared } \\
(\%)^{\mathrm{c}}\end{array}$ \\
\hline $\begin{array}{l}\text { Total variance of the multiple regression } \\
\text { model (incl. } 13 \text { comorbidity groups) }\end{array}$ & & & 13.07 & & & 13.48 \\
\hline $\begin{array}{l}\text { Predicted AQoL-8D of those without } \\
\text { comorbidities (Reference) }\end{array}$ & $0.43(0.40,0.47)$ & & & $0.66(0.63,0.70)$ & & \\
\hline \multicolumn{7}{|l|}{$\begin{array}{c}\text { Comorbidity groups and individual } \\
\text { comorbidities }\end{array}$} \\
\hline Mental health disorders & & & 9.92 & & & 2.54 \\
\hline Depression & $0.31(0.27,0.35)$ & $-0.12(-0.15,-0.10)$ & & $0.57(0.52,0.61)$ & $-0.09(-0.12,-0.06)$ & \\
\hline Anxiety & $0.34(0.29,0.38)$ & $-0.09(-0.12,-0.06)$ & & $0.58(0.53,0.63)$ & $-0.08(-0.11,-0.04)$ & \\
\hline Musculoskeletal disorders & & & 0.72 & & & 4.68 \\
\hline Osteoporosis & $0.38(0.33,0.43)$ & $-0.06(-0.09,-0.02)$ & & $0.60(0.55,0.66)$ & $-0.06(-0.10,-0.02)$ & \\
\hline Osteoarthritis & $0.41(0.36,0.45)$ & $-0.02(-0.06,0.01)$ & & $0.67(0.62,0.72)$ & $-0.05(-0.09,-0.02)$ & \\
\hline Rheumatoid arthritis & $0.41(0.32,0.50)$ & $-0.02(-0.11,0.06)$ & & $0.55(0.45,0.66)$ & $-0.11(-0.20,-0.01)$ & \\
\hline Systemic lupus erythematosus & $0.36(0.25,0.47)$ & $-0.07(-0.18,0.03)$ & & $0.49(0.37,0.61)$ & $-0.17(-0.28,-0.05)$ & \\
\hline Endocrine and Metabolic diseases & & & 0.59 & & & 1.23 \\
\hline High cholesterol & $0.43(0.39,0.48)$ & $-0.00(-0.03,0.03)$ & & $0.66(0.61,0.71)$ & $0.00(-0.04,0.03)$ & \\
\hline Type 1 diabetes & $0.37(0.24,0.49)$ & $-0.06(-0.19,0.06)$ & & $0.58(0.45,0.71)$ & $-0.08(-0.21,0.05)$ & \\
\hline Type 2 diabetes & $0.37(0.30,0.44)$ & $-0.06(-0.12,-0.01)$ & & $0.63(0.56,0.71)$ & $-0.03(-0.09,0.04)$ & \\
\hline Hyperthyroidism & $0.35(0.27,0.43)$ & $-0.08(-0.16,-0.01)$ & & $0.56(0.47,0.65)$ & $-0.10(-0.18,-0.03)$ & \\
\hline Hypothyroidism & $0.41(0.35,0.47)$ & $-0.02(-0.07,0.02)$ & & $0.62(0.56,0.68)$ & $-0.04(-0.09,0.01)$ & \\
\hline Diseases of the nervous system & & & 0.42 & & & 1.15 \\
\hline Epilepsy & $0.39(0.26,0.52)$ & $-0.04(-0.17,0.09)$ & & $0.55(0.41,0.70)$ & $-0.11(-0.25,0.03)$ & \\
\hline Migraine & $0.40(0.35,0.44)$ & $-0.04(-0.07,-0.01)$ & & $0.58(0.53,0.63)$ & $-0.08(-0.12,-0.05)$ & \\
\hline
\end{tabular}


Impact of comorbidities on HRQoL of people with MS

Diseases of the circulatory system

Hypertension

Heart diseases

Myocardial infarction

Stroke

Peripheral vascular disease

Diseases of the digestive system

Inflammatory bowel disease

Coeliac disease

Eye diseases

Allergies

Other autoimmune diseases

Diseases of the skin

Psoriasis

Diseases of the blood

Anaemia

Neoplasms

Cancer

Diseases of the genito-urinary system

Chronic renal disease

$$
\begin{aligned}
& 0.43(0.39,0.48) \\
& 0.40(0.33,0.46) \\
& 0.45(0.35,0.55) \\
& 0.42(0.33,0.51) \\
& 0.39(0.31,0.48)
\end{aligned}
$$

$0.37(0.28,0.45)$

$0.48(0.35,0.60)$

$0.40(0.35,0.45)$

$0.41(0.36,0.45)$

$0.40(0.33,0.47)$

$0.40(0.34,0.46)$

$0.44(0.39,0.50)$

$0.43(0.38,0.48)$

$-0.01(-0.04,0.03)$

$0.36(0.25,0.48)$

$0.00(-0.03,0.03)$

$0.02(-0.08,0.11)$

$-0.01(-0.09,0.07)$

$-0.04(-0.11,0.04)$

$-0.07(-0.14,0.01)$

$0.04(-0.07,0.16)$

$-0.03(-0.07,0.01)$

$-0.02(-0.05,0.01)$

$-0.03(-0.10,0.03)$

$-0.03(-0.08,0.02)$

$0.01(-0.03,0.05)$

$-0.07(-0.18,0.04)$
0.08

$-0.04(-0.09,0.02)$

0.03

0.38

0.07

0.23

0.06

0.04
$0.64(0.59,0.69)$

$0.58(0.45,0.72)$

$0.61(0.56,0.66)$

$0.55(0.47,0.63)$

$0.61(0.54,0.67)$

$0.67(0.61,0.72)$

$0.66(0.61,0.72)$

0.92

$0.00(-0.03,0.03)$

$-0.03(-0.09,0.03)$

$-0.01(-0.11,0.09)$

$-0.04(-0.13,0.05)$

$-0.06(-0.14,0.03)$

$\mathbf{- 0 . 1 0}(\mathbf{- 0 . 1 8}, \mathbf{- 0 . 0 2})$

$-0.07(-0.20,0.05)$

$-0.02(-0.06,0.02)$

$\mathbf{- 0 . 0 5}(\mathbf{- 0 . 0 8 ,}, \mathbf{- 0 . 0 2})$

0.90

0.36

0.40

0.36

0.09

0.04

$0.64(0.51,0.76) \quad-0.02(-0.14,0.10)$

${ }^{a}$ Doctor-diagnosed comorbidities refer to any comorbidity the patient reported as diagnosed by a doctor-

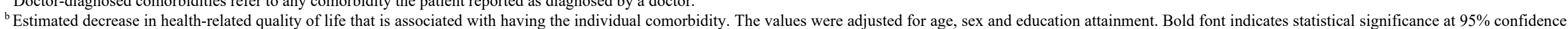

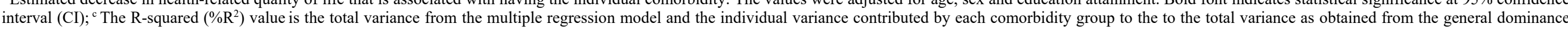
analysis.

AQoL-8D: Assessment of Quality of Life with eight dimension 